\title{
The Mind Anchor: Peran Trait Rumination dalam Struktur Pengalaman Afektif
}

\author{
Rinanda Rizky Amalia Shaleha, Cleoputri Al Yusainy, Ika Herani \\ rinandarizkyas@gmail.com \\ Jurusan Psikologi, Universitas Brawijaya, Malang, Indonesia
}

\begin{abstract}
This study aimed to investigate whether trait rumination has a role in individual's structure of current affect, specifically on valence and arousal dimension. Within-subject experiment design was used as a study design which involved eighty-one undergraduate students of Department of Psychology, Universitas Brawijaya as participants. Images from International Affective Picture System (IAPS) were used to evoke participant's affect and measured by Self Assessment Manikin's (SAM) rating while trait rumination was measured using Ruminative Response Scale (RRS). Statistical analysis using one-way repeated measures ANOVA technique found that trait rumination has a significant role in participant's structure of current affect on relation between valence stimulus and rating valence $(F=5.276$, $p<0.01)$ but has no role on relation between arousal stimulus and rating arousal $(F=0.753$, $p>0.05)$.
\end{abstract}

Keywords: arousal; International Affective Picture System; Ruminative Response Scale; trait rumination; valence

Penelitian ini bertujuan untuk mengetahui apakah trait rumination memiliki peran dalam struktur pengalaman afektif individu, yaitu dimensi valence dan arousal. Penelitian ini menggunakan desain within-subject experiment dengan melibatkan delapan puluh satu orang mahasiswa baru Prodi Psikologi Universitas Brawijaya sebagai partisipan. Afek partisipan dibangkitkan menggunakan stimulus gambar dari International Affective Picture System (IAPS) yang diukur melalui Self Assessment Manikin (SAM) dan trait rumination diukur menggunakan Ruminative Response Scale (RRS). Hasil analisis statistik menggunakan teknik one-way repeated measures ANOVA menunjukkan bahwa trait rumination memiliki peran signifikan dalam hubungan antara valence stimulus dan rating valence $(F=5.276$, $p<0.01)$. Namun, trait rumination tidak memiliki peran dalam hubungan antara arousal stimulus dan rating arousal $(F=0.753, p>0.05)$.

Kata kunci: arousal; International Affective Picture System; Ruminative Response Scale; trait rumination; valence

Received: January 25, 2018 Accepted: May 4, 2018

How to cite: Shaleha, R. R. A., Yusainy, C. A., \& Herani, I. (2018). The mind anchor: Peran trait rumination dalam struktur pengalaman afektif. MEDIAPSI, 4(1), 47-55. doi: https://doi.org/10.21776/ub.mps.2018.004.01.5

\section{Pendahuluan}

Kita tidak bisa melepaskan diri dari unsur penting dalam kehidupan kita yaitu emosi-afek. Kita bisa menangis, tertawa, tersenyum, ataupun merenung karena adanya peran dari proses emosi-afek tersebut. Emosi yang telah melalui proses pemaknaan oleh kognisi disebut dengan afek dan proses tersebut bersifat disadari (Panksepp, 2010). Afek sendiri terbagi menjadi dimensi bipolar yang mencakup valence dan arousal (Barrett \& Russell, 1999). Valence merupakan dimensi hedonis yang bergerak dari perasaan menyenangkan (afek positif) hingga tidak menyenangkan (afek negatif), sementara arousal merujuk pada dimensi aktivasi yang bergerak dari perasaan tergugah dan menggebu-gebu (arousal tinggi) hingga perasaan tenang, malas dan mengantuk (arousal rendah). Kedua dimensi tersebut membentuk pengalaman afektif manusia.

Pengalaman afektif antara satu individu 
dengan individu yang lain pasti berbeda, begitu juga dengan respon yang diberikan terhadap pengalaman afektif tersebut. Dalam mengelola pengalaman afektif, banyak faktor yang memengaruhi salah satunya adalah trait. Salah satu trait yang dapat memengaruhi perbedaan pemaknaan atas pengalaman afektif adalah trait rumination.

Trait rumination didefinisikan sebagai pemikiran yang repetitif mengenai perasaan negatif, penyebabnya, maknanya, dan akibatnya (Nolen-Hoeksema, Wisco, \& Lyubomirsky, 2008). Seseorang dengan kecenderungan trait rumination yang tinggi akan memikirkan kejadian yang dialaminya dengan berpikir secara mendalam mengapa hal tersebut bisa terjadi dan apa akibat dari kejadian tersebut yang akhirnya membuat individu semakin memiliki perasaan negatif terhadap kejadian yang menimpanya. Hal tersebut dapat dianalogikan seperti jangkar kapal, di mana jangkar kapal membuat kapal tidak berpindah tempat selama berada di atas air. Sama seperti orang dengan trait rumination yang tinggi, di mana orang tersebut seperti terjangkar atau tidak bisa beralih dari perasaan negatifnya. Siapapun bisa mengalami rumination dan sifatnya cenderung stabil, terlepas dari fluktuasi mood yang tengah dialami oleh subjek yang bersangkutan baik ketika subjek dalam keadaan bahagia maupun dalam keadaan sedih.

Pada dasarnya trait rumination mampu membantu individu agar memperoleh makna dan solusi dari suatu kejadian, namun ketika individu tidak dapat mengontrolnya maka trait rumination bisa berubah menjadi merugikan. Individu menjadi kesulitan mengontrol responnya terhadap kejadian negatif yang dialaminya, mengalami kesulitan dalam mengarahkan atensinya agar menjauh dari kesedihannya (Joorman, 2006), dan merasa pesimis terhadap masa depannya (Thomsen, Tonnesvang, Schnieber, \& Olesen, 2011).

Beberapa studi menjelaskan bahwa trait rumination berhubungan dengan mekanisme yang terkait dengan paparan stres terhadap peningkatan afek negatif. Peristiwa hidup yang penuh tekanan dapat meningkatkan rumination (Michl, McLaughlin, Shepherd, \& NolenHoeksema, 2013). Dalam penelitian yang dilakukan oleh Sinatra, Curci, Palo, dan Monacis (2011), trait rumination memiliki hubungan positif dengan gangguan depresi. Individu dengan level trait rumination yang tinggi dapat mengalami simtom-simtom depresi dan episode depresi mayor sehingga dapat memicu individu untuk memiliki ide bunuh diri (Nolen-Hoeksema \& Morrow, 1993). Penelitian terdahulu oleh Miranda, Tsypes, Gallagher, dan Rajappa (2013) yang berjudul "Rumination and Hopelessness as Mediators of the Relation Between Perceived Emotion Dysregulation and Suicidal Ideation" juga menyebutkan bahwa trait rumination berperan dalam meningkatkan kecenderungan individu untuk bunuh diri. Hubungan tersebut terjadi karena salah satu faktor dari trait rumination, yaitu brooding (mengkritik dirinya sendiri tanpa disertai dengan upaya proaktif untuk menyelesaikan masalah), dapat meningkatkan valence negatif dan level arousal individu sehingga menyebabkan disregulasi afek yang berujung pada ide untuk bunuh diri.

Nolen-Hoeksema, dkk (2008) menjelaskan bahwa trait rumination juga dapat menghambat proses pemecahan masalah, menurunkan motivasi dan inisiatif, serta merusak dukungan sosial. Meskipun seseorang menghasilkan solusi dari suatu permasalahan, trait rumination bisa menghalanginya untuk 
menerapkan solusi yang telah dibuat karena subjek akan kembali memikirkan masalah yang sudah terjadi dan terpaku pada hal tersebut (Lyubomirsky, Tucker, Caldwell, \& Berg, 1999). Terlalu fokus berpikir dan merenungi penyakit yang diderita juga menghambat pemulihan pada pasien yang mengidap penyakit kardiovaskular (Brosschot, Gerin, \& Thayer, 2006).

Dari pemaparan-pemaparan tersebut, kita dapat melihat bahwa trait rumination menghambat individu dalam mengelola pengalaman afektifnya dengan meningkatkan afek negatif yang dirasakan sehingga dapat mengubah perilaku individu ke arah yang maladaptif. Oleh karena itu, fokus dari penelitian ini adalah untuk mengetahui sejauh mana trait rumination memiliki peran terhadap valence dan arousal individu, yang mana valence dan arousal adalah dua dimensi pembentuk struktur pengalaman afektif. Hipotesis yang diajukan dalam penelitian ada dua, yaitu:

1. Trait rumination memiliki peran dalam hubungan antara valence stimulus dan rating valence.

2. Trait rumination memiliki peran dalam hubungan antara arousal stimulus dan rating arousal.

\section{Metode}

\section{Desain penelitian}

Penelitian ini merupakan penelitian replikasi dari Yusainy (2017) dengan menggunakan metode kuantitatif eksperimen. Namun, berbeda dari penelitian Yusainy, stimulus IAPS yang disajikan dalam penelitian ini menggunakan norma dari Huang, dkk (2015) karena dianggap lebih merepresentasikan norma untuk partisipan Asia mengingat penelitian ini dilakukan di
Indonesia. Desain penelitian yang digunakan adalah within-subjects experimental design dalam setting laboratorium. Penelitian ini melibatkan dua variabel independen yaitu stimulus valence yang memiliki tiga variasi (positif, negatif, netral) dan stimulus arousal yang memiliki dua variasi (tinggi, rendah). Selain itu, terdapat pula dua variabel dependen berupa rating valence dan rating arousal serta tiga variabel moderator yakni trait rumination, trait alexythimia, dan trait self-control. Peneliti sendiri berfokus untuk mengetahui peran trait rumination dalam struktur pengalaman afektif individu.

\section{Partisipan penelitian}

Partisipan penelitian adalah mahasiswa baru Program Studi Psikologi Fakultas Ilmu Sosial dan Ilmu Politik Universitas Brawijaya Malang angkatan 2015 yang menempuh mata kuliah biopsikologi. Jumlah total partisipan yang terlibat sebanyak 81 mahasiswa (25 lakilaki dan 56 perempuan). Sebagai imbalan, partisipan akan mendapatkan kompensasi kredit nilai kuis sebesar $10 \%$ dari mata kuliah Biopsikologi atas keikutsertaan mereka karena penelitian ini bekerjasama dengan dosen pengampu mata kuliah Biopsikologi.

\section{Data penelitian}

Data penelitian diperoleh dengan menggunakan beberapa intrumen penelitian. Instrumen utama penelitian yang digunakan yaitu International Affective Picture System (IAPS) versi terbaru tahun 2008 yang dikembangkan oleh Lang, Bradley, dan Cuthbert (2008). Instrumen IAPS terdiri dari ribuan gambar orang, objek, dan peristiwa yang merepresentasikan berbagai macam pengalaman manusia yang disajikan melalui layar komputer secara acak. Jumlah stimulus IAPS yang harus dinilai oleh partisipan adalah sebanyak 60 gambar. Partisipan diminta untuk 
menilai valence dan arousal dari gambargambar yang muncul dengan menggunakan rating Self Assessment Manikin (SAM). Pada dimensi valence, skor 1 ditunjukkan dengan gambar ekspresi cemberut, sedangkan skor 9 ditunjukkan dengan gambar ekspresi senyum. Pada dimensi arousal, skor 1 ditunjukkan dengan gambar ekspresi datar dan mata mengantuk, sedangkan skor 9 ditunjukkan dengan gambar ekspresi antusias dan mata terbuka lebar Skor rerata valence dan arousal yang diberikan partisipan terhadap masingmasing kategori gambar menghasilkan struktur pengalaman afektif. Sebelum melakukan penilaian terhadap stimulus IAPS, partisipan terlebih dahulu diminta untuk mengisi Ruminative Response Scales (RRS) yang terdiri dari 10 butir soal (5 butir soal dengan faktor reflection dan 5 butir soal dengan faktor brooding). Pada akhir eksperimen, partisipan diberikan video humor berdurasi kurang lebih 4 menit yang digunakan untuk menetralkan afek partisipan.

\section{Analisis data}

Data-data yang diperoleh dianalisis menggunakan teknik one-way repeated measures ANOVA dengan bantuan software SPSS versi 20.0 for Windows.

\section{Hasil}

\section{Preliminary dan reliability analysis}

Sebelum dilakukan interpretasi dan analisis terhadap data yang telah didapatkan, peneliti terlebih dahulu melakukan preliminary analysis menggunakan bivariate correlation untuk mengetahui korelasi dari variabel yang digunakan dalam penelitian ini. Dari preliminary analysis tersebut diketahui bahwa trait rumination memiliki korelasi positif terhadap stimulus valence positif dan berkorelasi negatif terhadap stimulus valence negatif. Kemudian peneliti melakukan reliability analysis untuk mengetahui reliabilitas dari instrumen utama yang digunakan pada penelitian ini, yaitu skala Ruminative Response Scale (RRS) dan stimulus gambar dari International Affective Picture System (IAPS). Koefisien reliabilitas alpha Cronbach $(\alpha)$ disajikan pada Tabel 1.

Tabel 1

Reliabilitas Instrumen Skala RRS \& Stimulus IAPS

\begin{tabular}{lc}
\hline \multicolumn{1}{c}{ Instrumen } & $\boldsymbol{\alpha}$ Cronbach \\
\hline Ruminative Response Scale & 0.660 \\
\hline Stimulus Positif & 0.845 \\
\hline Stimulus Netral & 0.612 \\
\hline Stimulus Negatif & 0.806 \\
\hline Stimulus High Arousal & 0.867 \\
\hline Stimulus Low Arousal & 0.895 \\
\hline
\end{tabular}

Manipulation check

Untuk memastikan bahwa partisipan mampu membedakan stimulus afektif berdasarkan valence dan arousal yang seharusnya dibangkitkan oleh stimulus, maka dilakukan manipulation check terhadap data sesi practice.

Dari hasil analisis, diketahui bahwa terdapat perbedaan signifikan pada valence stimulus terhadap rating valence $(\mathrm{F}=231.035$, $\mathrm{p}<0.001)$ dan perbedaan signifikan dari arousal stimulus terhadap rating arousal ( $\mathrm{F}=64.194, \mathrm{p}<0.001)$. Hal tersebut berarti, valence stimulus mampu membangkitkan valence partisipan, demikian juga arousal stimulus mampu membangkitkan arousal partisipan. Selain itu, dapat diketahui juga bahwa partisipan mampu membedakan dengan baik antara stimulus positif dengan stimulus negatif $(F=334.762, p<0.001)$, stimulus netral dengan stimulus negatif $(\mathrm{F}=172.748$, $\mathrm{p}<0.001)$, maupun stimulus arousal tinggi dengan arousal rendah $(\mathrm{F}=64.194, \mathrm{p}<0.001)$. 
Nilai mean dari masing-masing kategori stimulus ditampilkan pada Gambar 1.

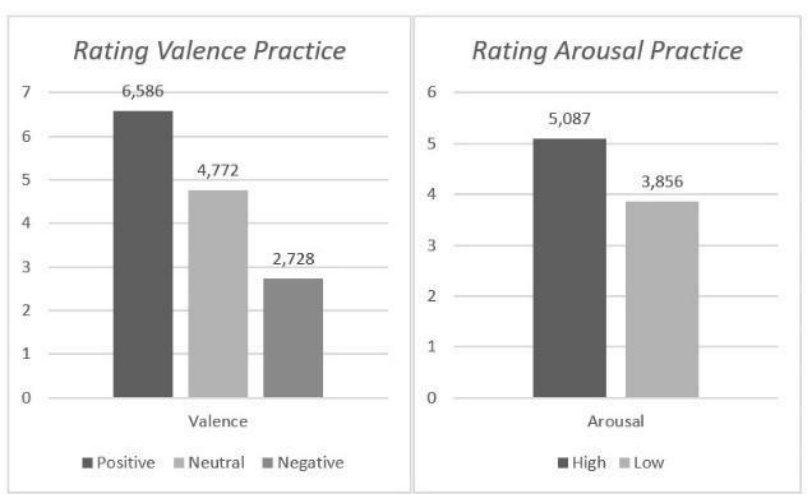

Gambar 1. Rating Valence dan Arousal terhadap Stimulus Afektif dan Nilai Mean (Sesi Practice)

\section{Uji hipotesis}

Analisis dilakukan sebanyak dua kali, yang pertama terhadap rating valence dan yang kedua terhadap rating arousal. Analisis menggunakan teknik one-way repeated measures pada data mean dari masing-masing kelompok stimulus IAPS terhadap rating valence dan rating arousal. Hasil analisis menunjukkan bahwa:

1. Trait rumination memiliki peran dalam hubungan antara valence stimulus dan rating valence $(F=5.276, p<0.01)$ sehingga dapat disimpulkan bahwa terdapat bukti yang kuat untuk melawan hipotesis nol yaitu trait rumination tidak memiliki peran dalam hubungan antara valence stimulus dan rating valence. Analisis lebih lanjut dengan menggunakan post-hoc test, diperoleh hasil bahwa trait rumination memiliki peran yang signifikan terhadap ketiga valence stimulus yaitu positif, netral, dan negatif.

2. Trait rumination memiliki peran dalam hubungan antara arousal stimulus dan rating arousal $(F=0.753, \quad p>0.05)$, sehingga dapat disimpulkan bahwa terdapat bukti yang kuat untuk mendukung hipotesis nol yaitu trait rumination tidak memiliki peran dalam hubungan antara arousal stimulus dan rating arousal.

\section{Analisis tambahan}

Dalam analisis tambahan ini, peneliti menguji peran dari dua dimensi trait rumination yaitu brooding dan reflection dalam struktur pengalaman afektif. Dari data yang diperoleh, ditunjukkan bahwa dimensi brooding memiliki peran dalam hubungan antara valence stimulus dan rating valence $(F=3.220, \quad p<0.05), \quad$ sebaliknya dimensi reflection tidak memiliki peran dalam hubungan antara valence stimulus dan rating valence $(F=0.819, p>0.05)$. Kemudian dimensi brooding memiliki peran dalam hubungan antara arousal stimulus dan rating arousal $(F=6.626, p<0.05)$. Dimensi reflection juga memiliki peran dalam hubungan antara arousal stimulus dan rating arousal $(F=13.995, p<0.01)$.

\section{Diskusi}

\section{Pembahasan utama}

Terkait dengan peran trait rumination dalam struktur pengalaman afektif, peneliti berhasil membuktikan hipotesis yang mengasumsikan bahwa trait rumination memiliki peran dalam struktur pengalaman afektif.

Trait rumination secara signifikan terbukti memiliki peran dalam hubungan antara stimulus valence dan rating valence. Sebagaimana kita ketahui bahwa area yang teraktivasi ketika seseorang distimulasi dengan valence stimulus yaitu area prefrontal cortex (termasuk dorsolateral prefrontal cortex) (Colibazzi, dkk, 2010). Hal tersebut menjadi berhubungan dengan penilaian individu terhadap rating valence karena area prefrontral cortex berfungsi memberi informasi dari semua indera dan 
menggabungkan informasi tersebut sehingga berguna untuk membentuk penilaian. Aktivasi pada area yang sama juga terjadi pada individu dengan trait rumination. Ketika trait rumination meningkat maka aktivasi pada area tersebut juga meningkat (van der Meer, Costafreda, Aleman, \& David, 2010). Johnson, Nolen-Hoeksema, Mitchell, dan Levin (2009) juga menjelaskan bahwa aktivitas pada area prefrontal cortex semakin meningkat ketika nilai trait rumination semakin besar. Hasil dari analisis tersebut sesuai dengan analisis awal dimana rumination berkorelasi dengan stimulus valence negatif dan stimulus valence positif, yang berarti trait rumination cenderung bermain pada tataran dimensi valence daripada arousal.

Barret (2006) menjelaskan bahwa valence dianggap sebagai dasar kehidupan emosional seseorang yang berasal dari kapasitas pikiran manusia untuk terlibat dalam proses penilaian (menilai apakah sesuatu itu bermanfaat atau berbahaya bagi dirinya) sehingga dalam menilai stimulus yang diberikan, individu cenderung akan melakukan penilaian apakah stimulus tersebut relevan atau tidak baginya. Ketika individu dengan kecenderungan trait rumination menilai stimulus dan menganggap bahwa hal tersebut relevan dengan kehidupannya (kejadian negatif), maka penilaian individu terhadap stimulus tersebut bisa jadi akan berbeda dengan penilaian-penilaian sebelumnya. Lohani, Gupta, \& Srinivasan (2013) dalam studinya tentang norma lintas budaya pada stimulus gambar IAPS di India mengemukakan bahwa relevansi kultural dari konten gambar perlu dijadikan bahan pertimbangan dalam penggunaan stimulus IAPS.

Lebih lanjut, trait rumination tidak memiliki peran dalam hubungan antara arousal stimulus dan rating stimulus karena memang berbeda pada area aktivasi otak, dimana area yang teraktivasi adalah area thalamus, amygdala, dan premotor cortex (Colibazzi, dkk, 2010).

\section{Pembahasan analisis tambahan}

Selain analisis utama tersebut, hasil dari analisis tambahan juga perlu dipertimbangkan. Analisis tambahan ini menguji peran dari dua dimensi trait rumination yaitu brooding dan reflection dalam struktur pengalaman afektif. Dari data yang diperoleh, ditunjukkan bahwa dimensi brooding memiliki peran dalam hubungan antara valence stimulus dan rating valence, sebaliknya dimensi reflection tidak memiliki peran dalam hubungan antara valence stimulus dan rating valence. Kemudian dimensi brooding memiliki peran dalam hubungan antara arousal stimulus dan rating arousal. Dimensi reflection juga memiliki peran dalam hubungan antara arousal stimulus dan rating arousal.

Peran brooding dalam hubungan antara stimulus valence dan rating valence terkait dengan aktivitas prefrontal cortex (area aktif ketika distimulasi stimulus valence) yang mana aktivitas prefrontal cortex meningkat pada saat individu melakukan self-blame (Colibazzi, dkk, 2010; Lemogne, dkk, 2009).

Brooding yang juga disebut sebagai selfblame digambarkan sebagai kecenderungan individu untuk terus menerus mengkritik dirinya sendiri tanpa disertai dengan upaya proaktif untuk menyelesaikan masalah. Individu akan menilai buruk dirinya secara terus menerus akibat dari pengalaman negatif yang menimpanya.

Berdasarkan penelitian sebelumnya, brooding lebih meningkatkan valence negatif 
dan level arousal dari afek sehingga terjadi disregulasi afek dan lebih lanjut menyebabkan disregulasi perilaku. Lebih lanjut, melalui bivariate correlation diketahui bahwa brooding berkorelasi negatif dengan valence negatif individu, sehingga semakin tinggi brooding maka rating valence yang diberikan individu semakin kecil atau semakin negatif.

Dimensi kedua yaitu reflection memiliki peran dalam hubungan antara valence stimulus dan rating valence dan juga dalam hubungan antara arousal stimulus dan rating arousal. Reflection merupakan faktor yang bervalensi netral dan dapat mengurangi afek negatif yang dirasakan individu (Treynor, Gonzales, \& Nolen-Hoeksema, 2003). Faktor ini dijelaskan sebagai kecenderungan individu untuk berkontemplasi atau melakukan perenungan terhadap masalahnya dengan harapan bahwa hal tersebut dapat menghasilkan solusi sehingga bersifat lebih adaptif. Individu dengan reflection yang lebih tinggi cenderung akan menilai sesuatu dengan lebih netral dan cenderung rendah pada aktivasi arousalnya. Hal tersebut juga didukung oleh analisis awal dimana dimensi reflection berkorelasi positif dengan stimulus arousal rendah.

Berdasarkan hasil penelitian tersebut, peneliti mengambil kesimpulan bahwa trait rumination memiliki peran dalam hubungan antara valence stimulus dan rating valence. Hal tersebut berarti bahwa trait rumination yang dimiliki oleh individu memengaruhi penilaian individu terhadap stimulus gambar dalam hal rating valence. Selain itu, kesimpulan lain yang diperoleh adalah bahwa trait rumination tidak memengaruhi penilaian individu terhadap stimulus gambar dalam hal rating arousal.

Penelitian ini juga memiliki keterbatasan. Keterbatasan pada penelitian ini yaitu penilaian terhadap dimensi valence dan arousal masih menggunakan paradigma lapor diri atau self-report, dimana instrumen jenis ini sangat rentan dengan adanya faking sehingga partisipan cenderung menunjukkan respon yang nampaknya diinginkan oleh peneliti terlebih lagi dengan adanya reward.

Selain itu, waktu juga menjadi keterbatasan peneliti di mana proses stimulasi stimulus diterapkan secara singkat yaitu 6 detik saja yang mungkin akhirnya menyebabkan individu kurang memaknai stimulus yang disajikan.

Adapun saran yang dapat diberikan untuk penelitian selanjutnya yaitu perlu adanya replikasi penelitian untuk menambah bukti ilmiah yang ada mengenai peran trait rumination dalam struktur pengalaman afektif dan menjelaskannya melalui pengukuran berbasis neuroimaging dengan menggunakan fMRI (functional Magnetic Resonance Imaging). Replikasi penelitian selanjutnya dapat mempertimbangkan faktor perbedaan jenis kelamin untuk mengetahui apakah terdapat perbedaan peran trait rumination dalam struktur pengalaman afektif antara partisipan laki-laki dan partisipan perempuan. Kemudian, peneliti selanjutnya harus memastikan apakah stimulus yang disajikan benar- benar mampu membangkitkan afek partisipan. Apabila memungkinkan, peneliti selanjutnya dapat menggunakan stimulus afektif yang lain seperti videoclip atau stimulus audio sebagai perbandingan.

\section{Daftar Pustaka}

Barrett, L. F., \& Russell, J. A. (1999). The structure of current affect: Controversies and emerging consensus. Current Directions in Psychological Science, 
8(1), $\quad 10-14 . \quad$ doi: https://doi.org/10.1111/1467$\underline{8721.00003}$

Barrett, L. F. (2006). Valence is a basic building block of emotional life. Journal of Research in Personality, 40(1), 35-55. doi:

https://doi.org/10.1016/j.jrp.2005.08.00 $\underline{6}$

Brosschot, J. F., Gerin, W., \& Thayer, J. F. (2006). The perseverative cognition hypothesis: A review of worry, prolonged stress-related physiological activation, and health. Journal of Psychosomatic Research, 60(2), 113$124 . \quad$ doi: https://doi.org/10.1016/j.jpsychores.200 $\underline{5.06 .074}$

Colibazzi, T., Posner, J., Wang, Z., Gorman, D., Gerber, A., Yu, S., . . Peterson, B. S. (2010). Neural systems subserving valence and arousal during the experience of induced emotions. Emotion, 10(3), 377-389. doi: https://doi.org/10.1037/a0018484

Huang, J., Xu, D., Peterson, B. S., Hu, J., Cao, L., Wei, N., ... Hu, S. (2015). Affective reactions differ between Chinese and American healthy young adults: A cross cultural study using the international affective picture system. BMC Psychiatry, 15(60), 1-7. doi: https://doi.org/10.1186/s12888-0150442-9

Johnson, M. K., Nolen-Hoeksema, S., Mitchell, K. J., \& Levin, Y. (2009). Medial cortex activity, self-reflection and depression. Social Cognitive \& Affective Neuroscience, 4(4), 313-327. doi: https://doi.org/10.1093/scan/nsp022
Joorman, J. (2006). Differential effects of rumination and dysphoria on the inhibition of irrelevant emotional material: Evidence from a negative priming task. Cognitive Therapy and Research, 30(2), 149-160. doi: https://doi.org/10.1007/s10608-0069035-8

Lang, P. J., Bradley, M. M., \& Cuthbert, B. N. (2008). International affective picture system (IAPS): Affective ratings of pictures and instruction manual. Technical Report A-8. Gainesville, FL: University of Florida.

Lemogne, C., le Bastard, G., Mayberg, H., Volle, E., Bergouignan, L., Lehéricy, S., ... Fossati, P. (2009). In search of the depressive self: extended medial prefrontal network during selfreferential processing in major depression. Social Cognitive and Affective Neuroscience, 4(3), 305-312. https://doi.org/10.1093/scan/nsp008

Lohani M., Gupta R., \& Srinivasan N. (2013). Cross-cultural evaluation of the international affective picture system with an Indian sample. Psychological Studies, 58(3), 233-241. doi: https://doi.org/10.1007/s12646-0130196-8

Lyubomirsky, S., Tucker, K.L., Caldwell, N.D., \& Berg, K. (1999). Why ruminators are poor problem solvers: Clues from the phenomenology of dysphoric rumination. Journal of Personality and Social Psychology, 77(5), 1041-1060. doi: https://doi.org/10.1037/00223514.77.5.1041

Michl, L. C., McLaughlin, K. A., Shepherd, K., \& Nolen-Hoeksema, S. (2013). 
Rumination as a mechanism linking stressful life events to symptoms of depression and anxiety: Longitudinal evidence in early adolescents and adults. Journal of Abnormal Psychology, 122(2), 339-352. https://doi.org/10.1037/a0031994

Miranda, R., Tsypes, A., Gallagher, M., \& Rajappa, K. (2013). Rumination and hopelessness as mediators of the relation between perceived emotion dysregulation and suicidal ideation. Cognitive Therapy and Research, 37(4), 786-795. doi: https://doi.org/10.1007/s10608-013$\underline{9524-5}$

Nolen-Hoeksema, S., \& Morrow, J. (1993). Effects of ruminationand distraction on naturally occurring depressed mood. Cognition and Emotion, 7(6), 561-570. doi:

https://doi.org/10.1080/0269993930840 $\underline{9206}$

Nolen-Hoeksema, S., Wisco, B. E., \& Lyubomirsky, S. (2008). Rethinking rumination. Perspectives on Psychological Science, 3(5), 400-424. doi: $\quad$ https://doi.org/10.1111/j.17456924.2008.00088.x

Panksepp, J. (2010). Affective neuroscience of the emotional BrainMind: evolutionary perspectives and implications for understanding depression. Dialogues in Clinical Neuroscience, 12(4), 533-545.

Sinatra, M., Curci, A., Palo, V., \& Monacis, L. (2011). How dialysis patients live: A study on their depression and associated factors in southern Italy. Psychology, 2(9), 969-977. doi: https://doi.org/10.4236/psych.2011.291 $\underline{46}$

Thomsen, D. K., Tonnesvang, J., Schnieber, A., \& Olesen, M. H. (2011). Do people ruminate because they haven't digested their goals? The relations of rumination and reflection to goal internalization and ambivalence. Motivation and Emotion, $35(2)$, 105-117. doi: https://doi.org/10.1007/s11031-0119209-x

Treynor, W., Gonzalez, R., \& NolenHoeksema, S. (2003). Rumination reconsidered: A psychometric analysis. Cognitive Therapy and Research, 27(3), 247-259.

doi: https://doi.org/10.1023/A:10239103155 $\underline{61}$

van der Meer, L., Costafreda, S., Aleman, A., \& David, A. S. (2010). Self-reflection and the brain: A theoretical review and meta-analysis of neuroimaging studies with implications for schizophrenia. Neuroscience \& Biobehavioral Reviews, 34(6), 935-946. doi: https://doi.org/10.1016/j.neubiorev.200 $\underline{9.12 .004}$

Yusainy, C. A. (2017). Feeling full or empty inside? Peran perbedaan individual dalam struktur pengalaman afektif. Jurnal Psikologi, 44(1), 1-17. doi: https://doi.org/10.22146/jpsi.18377 